applicability of half-vibrational quantum numbers to these bands, with the following result: Assuming half-integral values for $n^{\prime}$ and $n^{\prime \prime}$, the initial and final vibrational quantum numbers, with a minimum value $+\frac{1}{2}$, the band-origins of this system can be represented approximately by the equation

$\left.\nu=\begin{array}{l}19217 \\ 19224\end{array}\right\}+\left(\mathrm{I} 603 \cdot 5 n^{\prime}-34 \cdot 75 n^{\prime 2}\right)$

$-\left(\mathrm{I} 493 \cdot 5 n^{\prime \prime}-3 \mathrm{I} \cdot 25 n^{\prime \prime 2}\right)$

Placing the values of these coefficients in the equation for the vibrational isotopic displacement as given by Mulliken, ${ }^{4}$ and taking the isotopes of magnesium to be 24,25 , and 26 , one readily computes that for the $\frac{1}{2} \rightarrow \frac{1}{2}$ band,

$$
\begin{aligned}
& v_{25}^{n}-v_{24}^{n}=-0.042 \mathrm{~cm} .^{-1}, \\
& v_{26}^{n}-v_{24}^{n}=-0.082 \mathrm{~cm} .^{-1} .
\end{aligned}
$$

That is, the faint pairs of lines due to the less abundant isotopes 25 and 26 found on the low-frequency side of each strong doublet in the $Q$ and $R$ branches should be displaced by these amounts in addition to the (much larger) rotational isotopic displacement (also to the red). As a matter of fact, of 27 recorded pairs of Mg (26) lines, every one is displaced farther from the Mg (24) pair than is allowable as a pure rotational isotopic effect. The average increased displacement is $-0.073 \mathrm{~cm} .^{-1}$, which is in good agreement with the theoretical value $-0.082 \mathrm{~cm} .^{-1}$, considering the smallness of the shift. For the $\mathrm{Mg}$ (25) pairs the agreement is not quite so satisfactory (the measurements of the lines being less accurate), the observed average increased displacement, however, being fair, $-0.029 \mathrm{~cm}^{-1}$, as opposed to $-0.042 \mathrm{~cm}^{-1}$, as given by the theory. It is to be concluded, then, from these results that the vibrational quantum numbers in this band system must be given halfintegral values.

Ryerson Physical Laboratory,

University of Chicago. April 3

\section{Origin of Yolk in the Eggs of Spiders.}

IN a remarkable paper on the oocyte of Pholcus phalangiodes published in the last century (Arch. de Biol., tome I5, I898), Van Bambeke described a juxta-nuclear ring, the pallial layer or the pallial substance (see Wilson's "The Cell," third edition, p. 340), which with the growth of the oocyte separates from the nucleus, and, after fragmenting finely throughout the cytoplasm directly, gives rise to fatty deutoplasm. He also described ordinary yolk spheres which are albuminous in nature and arise independently in the cytoplasm.

During the last winter I have been working on the eggs of the common spider in Patiala, and I have been very much impressed by the remarkable accuracy of Van Bambeke's account in spite of the serious shortcomings of the technique (so far as the fixation of lipoids is concerned) in vogue in his time. I have shown that the pallial layer of Van Bambeke really consists of granular mitochondria, embedded in which are the Golgi elements in the form of rings or crescents. Indeed, Van Bambeke figures granules and rings in his pallial substance, but naturally he was not able to identify them. Mitochondria, of course, had been discovered earlier, but the Golgi apparatus was not yet known.

I strongly confirm Van Bambeke's statement that there are two kinds of yolk in the egg of spidersfatty and albuminous. Further, his statement that the albuminous yolk arises de novo, and the fatty yolk is derived from the pallial substance, is correct.

- Phys. Reviere, 25, x27, 1925.

$$
\text { NO. 2950, VOL. II } 7]
$$

Now the pallial substance consists of mitochondria and the Golgi elements. Is the fatty yolk derived from the mitochondria or from the Golgi elements? I have proved that the Golgi elements are directly metamorphosed into the fatty yolk, as in Lithobius (Nath, Proc. Camb. Phil. Soc. Biol. Sci., r924), Helix aspersa (Brambell, Brit. Jour. Expt. Biol. vol. I), Saccocirrus (Gatenby, Quart. Jour. Micr. Sci., I922), Patella (Ludford, J.R.M.S., I9I 8), and possibly in Palamnæus (Nath, Proc. Roy. Soc., London, I925). The mitochondria remain unchanged. A full account will be published later.

$$
\begin{gathered}
\text { Bhupindra Research Laboratory, } \\
\text { Mohindra College, Patiala, India. } \\
\text { April } 7 .
\end{gathered}
$$

\section{On the Occurrence of $2 n+1$ and other Chromosomal Mutants.}

Chromosomal mutants with one extra chromosome (or the corresponding $n+\mathrm{I}$ gametes) have been found in Oenothera, Datura, Matthiola, Nicotiana, Uvularia, and perhaps Mirabilis. It seems probable that they could be found in many other plants, if investigation ad hoc were made, either as somatic or gametic mutations. Such $2 n+\mathrm{r}$ offspring have also been found fairly often in Drosophila, and doubtless occur in other animals.

We have now a tolerably rapid method for counting the chromosomes of mammals, by the use of pieces of the amnion, stained with hæmatoxylin, and

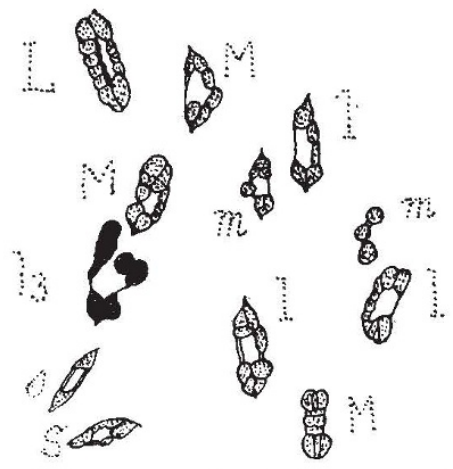

Fig. r.--Group of chromosomes of $2 n+1$ Datura mutant with an extra No. III. chromosome. Metaphase of reduction division. Camera drawing showing one trivalent and eleven bivalents.

mounted in balsam. It is possible that portions of this membrane may be examined directly in ironacetocarmine. In this case the chromosomal number of individual mammals could often be rapidly determined at birth. It would be of especial interest to know whether $2 n+I$ forms occur in man. There should be, of course, 24 possible $2 n+I$ forms in Homo (disregarding the $\mathrm{Y}$ chromosome), which is the same number as in tobacco. The possible occurrence of haploids, triploids, or tetraploids in mammals (as in several plants and in Drosophila) is also of interest since $2 n$ gametes have been seen (Painter) in Homo It is hoped that investigations may be made on this point in mice, rats, or guinea-pigs.

\section{Carnegie Institution of Washington,}

JohN Belling. Cold Spring Harbor, N.Y.

Errata.- "The Problem of X-Ray Line Intensities" : NATURE of May I, p. 622. Paragraph 3, line 4 , for 0.030 read 0.093 ; line 12 , for $80.04 \mathrm{~cm}$. read $8.04 \mathrm{~cm}$. 